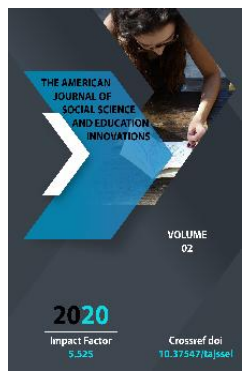

Journal Website: http://usajournalshub.c om/index,php/tajssei

Copyright: Original content from this work may be used under the terms of the creative commons attributes 4.0 licence.

\section{The Predisposition Of Deferential Tenderness Of Stag At Pirganj Upazila Of Bangladesh}

\author{
LU Kokum \\ Department Of Pharmacology, Bangladesh Agricultural University, Bangladesh
}

M Shahiduzzaman

Department Of Parasitological, Bangladesh Agricultural University, Bangladesh

\title{
ABSTRACT
}

The Predisposition of deferential Tenderness in Paragon of Rampur area was concentrated from January to December 2010. 100 and forty Stags of various ages in various seasons were researched for deferential ailments. The ailment was analyzed by clinical and physical assessments. The excrement were inspected by direct smear strategy following fixation by sedimentation and floatation procedures so as to recognize gastro intestinal parasites. Other end deferential ailments were analyzed based on explicit side effects. The Stags were likewise analyzed for ecto deferential pervasion. The ectoparasites were gathered by hand picking or by utilizing hair brush and analyzed under magnifying instrument for morphological examinations. The outcomes uncovered that the general Predisposition of endodeferential illnesses was $60.71 \%$ and ecto deferential Tenderness 15.71\%. Grown-ups are more powerless for both ecto and endo deferential pervasion. By and large Predisposition of endodeferential ailments was discovered higher in blustery season and ecto deferential invasion in summer season. The investigation make consideration that the Stags in Pirgonj experiencing various deferential infections and proposes that treatment and control measures ought to be taken to keep the Stag populace out of deferential ailments.

\section{KEYWORDS}

End parasite, ectoparasite, Stag, paragon

\section{INTRODUCTION}

The commitment of the animals segment to the GDP is around $25.21 \%$. It produces about $13 \%$ of absolute unfamiliar trade profit and gives all day work to about $20 \%$ and fractional work to about half of the provincial populace. Bangladesh has 20.75 million Stags at present. 
Dark Bengal Stags are exceptionally favored due to their top notch meat and skin in this nation, as in different nations of the world. Ranchers are keen on raising Stags because of their courteous conduct, low food admission, most noteworthy richness rate and numerous joking effectiveness. Provincial individuals back over $98 \%$ of absolute Stags in Bangladesh. About $65 \%$ of the absolute populaces in Bangladesh are neediness blasted and about 55\% rancher having no or next to no land for their property just. As steers and bison raising requires significant expense, the landless and negligible ranchers lean toward raising of Stags' Raising of Stags require a little venture with a little danger. Thinking about these realities, the Bangladesh Government has taken up a huge scope program as "Public Program for Poverty Alleviation through Stag Development". Nonetheless, it merits referencing that the staggering infections in Stags can be devastation if not appropriately tended to. Parasitism professes to be one of the primary impediments in domesticated animals raising in Bangladesh.

\section{MATERIALS AND METHODS}

The current examination was directed from January to December 2010 in Pirganj upazilla, under Rangpur locale. Carpological assessment was done in the research center of veterinary medical clinic, Pirgonj. 100 and fourty Stags rising in free going framework were chosen haphazardly and their ages were 30 days to 2.5 years.

\section{Test assortment}

During test assortment points of interest of the creatures concerning their species, breed, age, sex and general body condition was recorded. Fecal examples (roughly $5 \mathrm{gm}$ ) were gathered legitimately from the rectum of the Stags and put into little plastic compartments, containing10 \% formalin. Mark portraying points of interest of the creature, town and date of assortment was placed in the mass of the plastic compartment. The examples were quickly moved to the neighborhood veterinary clinic and kept in cooler at $4^{\circ} \mathrm{C}$ temperature until further assessment. Both the immediate smear and sedimentation and buoyancy strategies depicted by Urquhart et al. (1996) were performed to screen out the positive examples. Ectoparasites were gathered from the various pieces of the body of the individual Stag by hand picking. At the point when required, little hairbrush plunged in ethanol was utilized for the assortment of ticks. The purpose of connection was spread with ethanol. Sufficient safety measures were taken to safeguard the mouthparts and members of the ectoparasites during assortment. Ectoparasites were saved in 70\% liquor in perfect, well-plug glass vials which were marked appropriately.

\section{Physical assessment}

Different physical assessments were done cautiously in conference of neighborhood veterinary specialist or upazilla domesticated animal's official and the discoveries were recorded. Close review were performed appropriately so as to watch the introducing signs, for example, anorexia, gauntness, unpleasant hair coat, loose bowels. Respiratory misery was related to the assistance of stethoscope. Per rectal temperature were recorded with the thermometer.

\section{Clinical assessment}

Hypothetical determinations of some deferential infections were done dependent 
on the history, clinical sign and manifestations and dung assessment. Net assessment of excrement was made for the identification of living or dead worms or for the discovery of the fragments of tapeworms. The creature body was analyzed for the presence of any noticeable ectoparasites. Ectoparasites were recognized by the keys and depictions given by Wall and Shearer (1999).

\section{RESULTS AND DISCUSSION}

Predominance of end parasites in Stags The general Predisposition of end deferential sicknesses in Stags was recorded $60.71 \%$ and ectoparasite was $15.71 \%$. The Predisposition of end deferential malady discovered higher in grown-up Stag contrasted with youthful and old. Higher predominance was watched for coccidiosis and neoscariasis in youthful Stag. Age related examinations of end parasite of Stag in Pirgonj propose that grown-up Stag is generally helpless to end deferential invasion. The Predisposition of fascioliasis in Stag in Pirgonj was $14.29 \%$ The age astute Predisposition of fascioliasis was practically identical with the investigation of Hossain et al., 2011. The Predisposition of paramphistomiasis was higher in grown-up and old Stag contrasted with youthful stage and discovered more in blustery season. This outcome is in corroborative with the investigation of Rahman (1969) however different examinations were unique may be because of local and ecological varieties. The pervasiveness of strongyloidosis was $5 \%$ which was not exactly those recorded by Morgan et al. (2006) by where the creator announced predominance of strongyloidosis in Stag. If there should arise an occurrence of neoscariasis pervasiveness was $2.14 \%$ which was not exactly those recorded by Tarazona (1974). Coenuriasis was discovered $3.57 \%$ in this examination and is practically identical with the investigation revealed by Nooruddin, et. al., 2000. The predominance of coccidiosis was $2.86 \%$ which was somewhat more than those recorded by Torina et al. 2004 and Rahman et al., 2012 where they announced the pervasiveness of coccidiosis was $1.85 \%$ and $1.40 \%$ separately.

\section{CONCLUSION}

The examination of ectoparasites in Stag in Pirgonj uncovered that grown-ups are more helpless to ecto deferential invasion followed by old and youthful. The ecto deferential invasion was discovered more in summer trailed by winter and stormy seasons. The general pervasiveness of ecto deferential invasion was $15.71 \%$. The general pervasiveness of lice invasion was higher than tick, mange and parasite invasion. These outcomes anyway vary from different investigations as the creators determined the pervasiveness rate contrasted with the absolute contaminated creatures. Rahman et al., detailed $2.54 \%$ predominance rate in Stag where they determined the Predisposition contrasted with complete number of researched creatures.

\section{REFERENCES}

1. Brito DC and Ollveria (1999). Veterinary Medicine .seventh edn. Balliere and Tindal, London. DLS (2014). Branch of Livestock Services, Goverment of Bangladesh.

2. MIS (2006). Division of Livestock Services, Govern ment of Bangladesh.

3. Malatyall (1990). Inlet of Bengal Program: Small Scale Communities. 